Practice Reflections

\title{
Group programs in corrections. Best practice meets real world:
} Some reflections on being neat in messy places

\section{Kevin O'Sullivan ${ }^{1}$}

School of Psychology, University of New South Wales, Australia (1) Until March 2013, Kevin was Director of the Offender Programs Unit CSNSW Abstract: The past decade has seen a very significant cultural shift in how group programs are delivered in prisons and in probation and parole settings in New South Wales, Australia. The agency responsible for custodial and community corrections services, Corrective Services New South Wales (CSNSW) is making its way from a culture of considerable autonomy, where staff largely wrote and ran group programs in the way that seemed best to them, to an organisation where systems exist for accreditation, training, supervision and systematic data collection. The transformation to model agency is not complete, but considerable progress has been made and this is borne out by the preparation and publication of a number of significant papers describing the outcomes of program interventions. This paper appraises the progress so far in the introduction of evidence-based group work and offers some reflections on the challenges faced in moving a large organisation concerned with security and offender supervision towards best practice in group rehabilitative programs.

Keywords: group programs; offender rehabilitation; group work training; program implementation; groupwork supervision; program integrity

1. School of Psychology, University of New South Wales / (until March 2013) Director of the Offender Programs Unit CSNSW,

Address for correspondence: Wentworth Forensic Clinic, 13-15 Wentworth Avenue, Darlinghurst, NSW 2010, Australia. kosullivan@psy.unsw.edu.au

Date of first (online) publication: 23rd May 2014

93 J. of Practice Teaching \& Learning 12(3), pp.93-109. DOI: 10.1921/7902120302. @ w\&bb 2014 


\section{Group rehabilitation programs in New South Wales}

Correctional services in many jurisdictions, including New South Wales (NSW), provide group rehabilitation programs to offenders because there is strong research evidence that programs with the right content, duration and delivery can significantly reduce the rate of re-offending. This can reduce the burden and cost to the criminal justice system and contribute to greater community safety.

Since the mid-1970s many hundreds of studies published about group programs with alcohol and drug-using offenders, sex offenders, violent offenders and others have been reviewed and analysed in a series of major studies called 'meta analyses' (analysis of the analyses) and in systematic reviews of research evidence that aim to summarise the overall effect that can be expected from well-planned and well-delivered interventions.

Typical of such studies were those conducted by Lipsey and Cullen (2007), Aos, Miller and Drake (2006) and Lowenkamp, Latessa and Holsinger (2006). Lipsey and Cullen (2007) found that the impact of rehabilitation treatment on reoffence rate was consistently positive and relatively large. Similarly, Aos, Miller and Drake (2006) systematically reviewed 571 evaluations of correctional programs and found that those which use proven evidence-based approaches have greater impact on reducing the likelihood of re-offending. Lowenkamp, Latessa and Holsinger (2006) found that residential and non-residential correctional programs that target offenders who are of higher risk of re-offending are more effective in reducing recidivism.

These studies point to several principles that underpin successful group work with offenders. The first (the Risk principle) states that more intensive treatments or interventions should target offenders who are at greatest risk of re-offending. Research has shown that not only are those at greatest risk likely to benefit most from interventions, but also that exposing low-risk offenders to inappropriate group programs may in fact increase their risk of re-offending (Andrew \& Bonta, 2006).

The second principle (the Needs principle) suggests that programs should focus on offenders' criminogenic needs (also known as risk factors or treatment targets), the characteristics that research has shown to be robust predictors of recidivism. These include anti-social attitudes/values, pro-criminal associates, impulsiveness or poor self-control (Goggin $\&$ Gendreau, 2006). Research has shown that the more of these needs are met

94 J. of Practice Teaching \& Learning 12(3), pp.93-109. DOI: 10.1921/7902120302. @ w\&b 2014 
in a given program, the greater the chance the program has of reducing re-offending (Skeem, Polaschek \& Manchak, 2009).

The third principle (the Responsivity principle) states that the way programs are delivered must take into account all the issues that may get in the way of the participants' ability to engage with and respond to the program. These include issues like the offenders' motivation and their learning style or literacy levels and ability to comprehend concepts. They also include the individual's social and interpersonal skills and style and his or her ability to exert sufficient behavioural control to participate in the group's work. The therapist's or program facilitator's skills, knowledge and style can also impact on the effectiveness of program delivery.

This paper describes the effort to implement these principles in NSW.

\section{The 'before' position in New South Wales}

Prior to the mid-1990s group programs provided to offenders in NSW lacked a basis in the findings of the relevant research literature. Programs were delivered with considerable autonomy: staff wrote and ran programs as they saw fit. There was no over-arching plan, strategy or direction for programs. Group work was done by those staff who wanted to do it. These were by and large Alcohol and Other Drugs Workers, many of whom used their personal experience of recovery to inform their practice. With very few exceptions, psychologists did not run programs. The exception to this rule was the Special Care Unit in Sydney that was run by Dr. David Schwartz and modelled on the Special Unit at Her Majesty's Prison Barlinnie in Scotland.

In 1994 senior psychology staff (including the author) were appointed to create new specialised programs for violent offenders, sex offenders and offenders who persistently self-harmed. These developments were scantily documented and accounts were practically never published, (but see for example O'Sullivan, 1996). Program units operated in considerable isolation from group programs in the rest of the agency. In general, there was no needs-based planning process or standardised assessment and offenders usually self-selected into programs. The other missing element was any systematic recording of who had done what program and indeed if such records had existed they might have been quite misleading. Many programs that differed in content and duration might have the same name: 'Anger Management' or 'Relapse Prevention'. Programs varied from

95 J. of Practice Teaching \& Learning 12(3), pp.93-109. DOI: 10.1921/7902120302. @ w\&bb 2014 
location to location and from custody to community. It was not unusual for an offender to be released on parole with a sheaf of certificates indicating program completion, only to be reassessed da capo for what was to happen under parole supervision.

At the end of the 1990s CSNSW began planning to incorporate the Risk, Needs, Responsivity model (Andrews \& Bonta, 1996) into correctional group programs (see for example the Best Practice Framework in Caruana, 1998). The scope of the task was large, with an average daily population of some 10,000 offenders in custody, with a major emphasis on security and safety, and around 18,000 under supervision in the community. The Probation and Parole Service had at various times been integrated with the custody service and at times had been separate, and the culture of the two arms was quite different. A brief summary of this 'Before' picture of correctional programs in NSW is found in Howells, et al. (2004).

The task of cultural change that would facilitate the introduction of evidence-based programs was approached using three major initiatives: (1) by compiling a set of accreditation criteria to choose its suite of offender programs (DCS 2003); (2) by providing comprehensive training for its group work facilitators; and (3) by providing ongoing support, quality monitoring and supervision. The main vehicle to drive these initiatives was the Offender Programs Unit.

\section{The Offender Programs Unit; Towards cultural change}

The creation of the Offender Programs Unit (OPU) has been described elsewhere (O'Sullivan, 2006). Similar to the Offending Behaviour Programs Unit in the UK Home Office, the OPU was tasked with the introduction and oversight of evidence-based group programs for offenders in custody and under supervision in the community. Initially there were ten staff from a variety of backgrounds including psychology, education and drug and alcohol counselling. The Unit began by first documenting existing provision and second by introducing change processes for program materials and for group work practice that would bring the agency into compliance with the framework.

96 J. of Practice Teaching \& Learning 12(3), pp.93-109. DOI: 10.1921/7902120302. @ w\&b 2014 


\section{Group program development: The Strategic Accreditation Framework and the Compendium of Programs}

The original Strategic Framework for Program Accreditation (DCS, 2003) provided for 'accredited' and 'approved' programs. 'Accredited' programs were to be those that targeted a reduction in re-offending, and 'approved' programs were to be those that did not target re-offending but were useful for the care, personal development and well-being of offenders. Accredited programs had to have a program sponsor who devised an accreditation submission demonstrating how the program met the accreditation criteria. The submission was then to be considered by an Accreditation Panel whose membership and functioning were undefined.

In 2005, a process was devised for preparing accreditation submissions and convening the Accreditation Panel and was applied to number of existing programs with varying results. What emerged from these first attempts at accreditation was that the process was cumbersome and timeconsuming. The program materials were extensive and were circulated to the panel members by mail. There was no set provision for the panel to ask questions of a program expert, nor to request further information, whether prior to or at the panel session. If further information was requested, it was not clear how or to whom that would be delivered and with what periodicity the panel would be reconvened to reconsider evidence. More importantly, it also became evident that the framework did not allow for the dynamic process of program development over time, from inception through design and implementation, process evaluation and outcome evaluation. This process may take many years and needs to be taken into account when appraising the worth of the program being offered.

It was also unclear just what the 'approved' category encompassed. The examples offered were the Health Promotion programs that targeted awareness and control of blood-borne viruses. Parenting programs were sometimes included in this category. It was also unclear whether programs such as relaxation, meditation and life skills would need to be 'approved' programs.

Staff constraints precluded any serious revision of the process until 2011 when a major revision of the framework was undertaken by staff of the OPU, with the publication of the Program Accreditation Framework (OPU, 2012).

Table 1 below sets out the accreditation levels and describes the meaning of each and the evidence required for inclusion. The Framework

97 J. of Practice Teaching \& Learning 12(3), pp.93-109. DOI: 10.1921/7902120302. @ w\&bb 2014 
Table 1

Levels of accreditation and their meaning (OPU 2012)

\begin{tabular}{|c|c|c|}
\hline Level / Status & Description & Criteria / Evidence \\
\hline $\begin{array}{l}\text { Level } 1 \\
\text { Accredited }\end{array}$ & $\begin{array}{l}\text { Confirmed accredited } \\
\text { programs have been } \\
\text { found to produce pro- } \\
\text { social change in offenders } \\
\text { attitudesand/or behaviours } \\
\text { AND } \\
\text { have at least one } \\
\text { qualified longitudinal } \\
\text { study completed which } \\
\text { demonstrates statistically } \\
\text { significant reductions } \\
\text { in offender risk or re- } \\
\text { offending. }\end{array}$ & $\begin{array}{l}\text { Fully meets all } 7 \text { criteria for accreditation. } \\
\text { Evidence of significant change in } \\
\text { behaviour/ cognition/attitudes/skills/ } \\
\text { or meeting other specific program goals } \\
\text { through } 1 \text { or more study utilising pre and } \\
\text { post program testing - or similar. } \\
\text { Plus - evidence from study using } \\
\text { experimental methodology (e.g. } \\
\text { Comparison control group design and } \\
\text { survival analysis) }\end{array}$ \\
\hline $\begin{array}{l}\text { Level } 2 \\
\text { Accredited }\end{array}$ & $\begin{array}{l}\text { Accredited programs have } \\
\text { been found to produce pro- } \\
\text { social change in offenders' } \\
\text { attitudes and/or behaviours. }\end{array}$ & $\begin{array}{l}\text { Fully meets all } 7 \text { criteria for accreditation. } \\
\text { Evidence of significant change in } \\
\text { behaviour / cognition / attitudes / skills } \\
\text { meeting other specific program goals } \\
\text { through } 1 \text { or more study design utilising a } \\
\text { minimum of pre and post program testing }\end{array}$ \\
\hline $\begin{array}{l}\text { Level } 3 \\
\text { Provisionally } \\
\text { Accredited }\end{array}$ & $\begin{array}{l}\text { Provisionally accredited } \\
\text { programs meet the criteria } \\
\text { for accreditation. The } \\
\text { Program Accreditation } \\
\text { Panel is awaiting evidence } \\
\text { on the efficacy of this } \\
\text { program. }\end{array}$ & $\begin{array}{l}\text { The program's design, development and } \\
\text { implementation meet all } 7 \text { criteria. } \\
\text { Peer review literature exists supporting } \\
\text { program efficacy and/or favourable } \\
\text { outcomes have been previously } \\
\text { demonstrated by this program in another } \\
\text { location or by similar programs. } \\
\text { Awaiting evidence on the efficacy of this } \\
\text { specific program }\end{array}$ \\
\hline $\begin{array}{l}\text { Level } 4 \\
\text { Registered } \\
\text { Program }\end{array}$ & $\begin{array}{l}\text { Not yet reviewed by the } \\
\text { Program Accreditation } \\
\text { Panel } \\
\text { May be a newly developed } \\
\text { or an existing Program } \\
\text { or considered useful by } \\
\text { CSNSW } \\
\text { Has potential for pro- } \\
\text { social attitude/behavioural } \\
\text { change or Duty of Care } \\
\text { needs }\end{array}$ & $\begin{array}{l}\text { Not yet submitted for accreditation. } \\
\text { Has Director, Offender Program Unit } \\
\text { endorsement for piloting based on his/ } \\
\text { her review of the program according to } \\
\text { the criteria }\end{array}$ \\
\hline $\begin{array}{c}\text { Not } \\
\text { Accredited } \\
\text { - No further } \\
\text { review }\end{array}$ & $\begin{array}{l}\text { Program Accreditation } \\
\text { Panel considers the program } \\
\text { is not relevant to CSNSW } \\
\text { goals and does not merit } \\
\text { further investigation. }\end{array}$ & $\begin{array}{l}\text { Doesn't meet sufficient criteria for } \\
\text { accreditation }\end{array}$ \\
\hline
\end{tabular}

98 J. of Practice Teaching E Learning 12(3), pp.93-109. DOI: 10.1921/7902120302. ( w w $b$ b 2014 
also provides guidance on the overall accreditation process as well as the resources to aid the assessment of the quality of the evidence presented. The new framework is more dynamic than the previous version, allowing for programs to be tested initially against the criteria and subsequently to be trialled in the field. This gives time for process evaluation as well as the collection of data such as pre- and post-testing results prior to the measurement of recidivism outcomes. Since 2012 the Accreditation Framework has been available online at http://www.correctiveservices. nsw.gov.au/.

In 2007 the Institute of Group Leaders in Australia adopted the CSNSW Accreditation Criteria as their own and made them available to all IGL members online at www.igl.org.au.

\section{The Compendium of Correctional Programs in New South Wales}

The data that the OPU collected on programs being offered were published in the Compendium of Correctional Programs in NSW. At first this was a descriptive document that simply listed the programs running in NSW and gave their locations. After the first edition, it became prescriptive in the sense that only programs contained in the Compendium were to be conducted in Correctional Centres and District Offices. In May 2006, this directive became agency policy. In all, six editions of the Compendium have been produced and the current edition, the Compendium of Correctional Programs in NSW (CSNSW, 2012), is now accessible online.

The difference between the programs in the Compendium and any other group activities that offenders may attend is that offenders may be directed to participate in Compendium programs as part of their case plan. By including programs in the Compendium, CSNSW indicates that it has subjected these to scrutiny and can vouch for their suitability as interventions that can reasonably be expected to contribute to a reduction in the risk of re-offending. In contrast, CSNSW does not make that claim for any program that is not included in the Compendium.

99 J. of Practice Teaching \& Learning 12(3), pp.93-109. DOI: 10.1921/7902120302. (C) wEb 2014 


\section{Training for Group Programs}

Prior to 2004 there was no comprehensive, systematic, agency-wide training for staff who facilitated programs, but several important initiatives did exist. Among these was an introductory training course in group work, a competency-based course conducted by the Brush Farm Corrective Services Academy, the in-house training organisation for CSNSW. This basic level training was mandatory for all Probation and Parole staff preparing to run groups. Apart from this brief course, most group-related training focussed on the content of the program manuals.

\section{Training in program content: The challenge of duplication}

A number of programs had mandatory program-specific training: the Sober Driver Program (drink driving), the Drug and Alcohol Addictions Program and the Think First Program (cognitive skills). These all had mandatory training packages, funded or not, lasting several days each.

Ad hoc training events were also held such as the Personal Effectiveness Program (PEP) training for staff at the Metropolitan Special Programs Centre (O'Sullivan, Haggett \& Clark 1997). As specialist programs like the Sex Offender and Violent Offender Programs were staffed exclusively by psychologists, it was assumed that staff brought with them the requisite knowledge and skills from their professional training to equip them for the task of running programs. This assumption has not always been justified.

As further programs were added to the Compendium that stipulated their own training requirements, it became clear that many requirements were common across programs, covering certain core elements. These were identified as: group work skills, motivational interviewing and an understanding of CBT. These were needed in addition to any familiarisation that is required in program-specific content.

The challenge for providing group work training on a program-byprogram basis was the sheer volume of the task. With a variety of programs, each having a training event of two, three or four days at a time, it became very difficult on the one hand, for managers to release staff and on the other, for trainers from OPU to cover the entire state-wide need. Feedback from managers was that the training demands were simply too disruptive to the day-to-day operations of the agency. Added to this, and perhaps

100 J. of Practice Teaching \& Learning 12(3), pp.93-109. DOI: 10.1921/7902120302. @ wEb 2014 
most importantly, there was no real concept or acknowledgement of group facilitation as a professional activity, requiring training, knowledge, skills and ongoing professional development over and above what might routinely be expected of a Probation and Parole Officer, a Drug and Alcohol Counsellor or other similar roles. Hence, managers were frequently surprised at the amount of training that the OPU was expecting staff to do.

\section{Training in group work skills}

The strategy to address this was to focus on improving training in the area of generic group facilitation skills rather than individual programs. Given that all programs are still manualised, it appeared more important to focus training on the ability of the facilitator to understand what is happening in the group room and to use the process skilfully to attain the ends of the group. A highly-skilled facilitator can more easily and dependably pick up a well-written manual and deliver the content in a way that preserves program integrity. In resource terms, this means that the OPU can concentrate training efforts on group work skills and spend relatively less time on program content that can be studied in the manual. This also leaves more time for the Program Support staff of the OPU to devote to ongoing supervision, support and quality monitoring.

Group work training is provided to suit three levels of expertise: basic, intermediate and advanced. Basic training in group work is provided by the nationally-accredited and competency-based Plan and Conduct Group Activities Course conducted by the Brush Farm Corrective Services Academy in Sydney. This offers an introduction to working with groups and covers such topics as group stages and dynamics, group work techniques, and how to plan and conduct training sessions. Successful completion earns a nationally recognised Statement of Attainment in the unit of competency CHCGROUP403D Plan and Conduct Group Activities in partial completion of CHC40708 Certificate IV in Community Service Work.

However, many staff come to CSNSW with training equivalent to this basic course. These staff have typically trained with non-government organisations (NGOs) who deliver services using group work such as Relationships Australia, the St. Vincent de Paul Society, Uniting Care Burnside or others. Some staff may have done group work skills training courses as part of academic degrees in social work or psychology. These staff can either apply to the Offender Programs Training Unit (OPTU)

101 J. of Practice Teaching \& Learning 12(3), pp.93-109. DOI: 10.1921/7902120302. @ w\&bb 2014 
for Recognition of Prior Learning (RPL) or they can apply for admission to Intermediate Level Training, the Creative Group Work Skills Course, described below.

The Creative Group Work Skills package is provided in two blocks of three days each, working to develop knowledge and skills relating to use of 'immediacy' and 'process' more so than in the Basic course. 'Process' in group work refers to all the interactions that happen between members in the group room, regardless of the content of the program. This training package is provided by staff of the OPU and is mandatory for all staff who deliver Compendium programs. Successful completion of this training program admits the staff member to the fast-track 'familiarisation' process described below. It also qualifies staff to apply for full membership of the Institute of Group Leaders. The first evaluation of this training program has been submitted for publication in 2013.

The Advanced Therapeutic Group Process package was a five-year joint project certificated by Macquarie University, Sydney and delivered by staff of the OPU. The program is based on the work of Irvine Yalom (Yalom \& Leszcz 2005) which in turn is based on the interpersonal psychology model of Harry Stack Sullivan (Sullivan 1953). The training program focuses on the participants' personal experience of being in a group as a necessary condition of understanding and using group process. It lasts around eight months in all, with ten face-to-face teaching days, workplace supervision and assignments. There are ten training places in each cohort. The core of the training is the daily training group, an unstructured activity that invites participants to stay in the here and now and reflect on their experiences within the group. Successful completion of this training is mandatory for the confirmation of newly-appointment specialist Program Facilitators and is open to all staff who regularly facilitate groups. The first evaluation of this training program is in preparation.

\section{Training in program content: A streamlined approach}

The strategy of focussing on training on group work rather than content has allowed for a new way of managing training in the use of program manuals. In practice, program manual training is delivered in a number of ways: it can be face-to-face, by e-learning or by 'familiarisation' with the manual. Face-to-face training is still required for a number of programs most notably the Domestic Abuse Program. Working with perpetrators of domestic abuse

102 J. of Practice Teaching \& Learning 12(3), pp.93-109. DOI: 10.1921/7902120302. @ w\&b 2014 
is a challenging task and experience has shown that not all staff are suited to this. E-learning is currently used with the CALM (Controlling Anger and Learning to Manage It) Program (Winogron, Van Dieten \& Gauza, 1997). The prospective facilitator follows an online training course, passes the set tests and is issued with a certificate of completion. E-learning has proved to be a useful adjunct to face-to-face training and further courses are likely to be constructed

'Familiarisation' is provided to staff who have successfully completed the Creative Group Work Skills course (see above). Staff who meet all requirements are issued with the program materials needed and are given several weeks to familiarise themselves with the manuals and other resources in their own workplace and at their own pace. Following this, OPU staff interview the trainees either by phone, video link or in person, to ascertain whether they have read the materials and whether they grasp the fundamentals of the program. If successful, the trainee is authorised to run the program and registered on the CSNSW Learning Management System.

\section{Supervising group programs: Ongoing support and quality monitoring}

To ensure well-designed programs are run by well-trained facilitators, the third element in the best practice approach is to maintain program integrity (also called 'program fidelity'). This means that the program needs to be run in the way that it was intended (Shaffer and Pratt, 2009). Ongoing program monitoring and support contributes to program integrity in two ways: (1) it ensures that program materials are presented in a consistent, clear and faithful way; and (2) it helps maintain facilitators' morale, commitment and professional practice in the face of an often challenging role.

The supervision of specialist Program Facilitators and other staff who deliver programs is therefore a major task for the OPU. To support this, the Program Supervision Framework was published in 2010 (OPU, 2010) and provides a quality assurance tool that can be applied to promote reflective practice and professional development of those involved in program delivery. The OPU provides supervision by conducting site visits, videotaped sessions, video conferencing and teleconferencing. The cultural challenge of introducing routine program supervision has been considerable. On

103 J. of Practice Teaching \& Learning 12(3), pp.93-109. DOI: 10.1921/7902120302. @ wEbb 2014 
the one hand, staff, particularly those without a professional background in social work or psychology were often reluctant to expose their practice to the gaze, however benevolent, of others. On the other hand, managers were often puzzled as to why ongoing supervision would be required at all: 'Why do they need supervision? Aren't they trained?'

An important element in defusing anxiety and securing compliance was to articulate clearly what exactly the supervisory process could offer to the group facilitator. This was done by sharing the supervision format and checklist with the facilitators and inviting him or her into a process of reflection on their work, both the aspects that went well and those where they felt they could have done differently and better. In general, supervisors are encouraged to adopt an appreciative enquiry approach. In using taped sessions, facilitators are encouraged to watch themselves and form their own views, as well as 'submitting' the tape for review and feedback.

The OPU provides supervision by conducting site visits, videotaped sessions, video conferencing and teleconferencing, and feedback covers four main areas: (1) adherence to program content, (2) adherence to treatment style, (3) group work skills and participant engagement, (4) responsivity and personal discretion. The feedback also summarises facilitator strengths and competencies and notes areas for learning and practice development.

At the time of writing, program supervision is arguably the most under-developed and under-resourced aspect of the OPU's work but is the key to ongoing quality and therefore to positive results. Without a process to monitor group program fidelity there can be no guarantee that what is being evaluated in eventual outcome studies is what was intended to be delivered. Without a process to support group facilitators in challenging environments there is likely to be a drift to lower morale and a higher turnover of expert staff.

\section{The challenges that remain}

We have attempted to describe how, in the last ten years, the Offender Programs Unit has attempted to lead a significant cultural change in the way that group programs for offenders are designed and delivered. The agency embraced the literature on evidence-based practice and particularly the Risk-Needs-Responsivity paradigm (Andrews $\&$ Bonta, 2006) and the Good Lives Model (Ward \& Stewart, 2003).

104 J. of Practice Teaching \& Learning 12(3), pp.93-109. DOI: 10.1921/7902120302. @ w\&b 2014 
From a starting point of considerable autonomy for facilitators, the first step was to restrict the group programs that were accredited to be run with offenders and to ensure that they were strictly manualised. Program fidelity was enforced through an allonomous process wherein control over group work was reserved to a central unit, the OPU, which was given say over what could and could not be done.

The second stage saw an increased focus on the person of the group facilitator and redoubled efforts to provide professional training and supervision in group work skills and experience. The creation of a specialist Program Facilitator role was important in this respect, as it emphasised that group work was not something that could be tagged on, as it had been in the past, to other disparate roles (Holland \& Sallabank, 2011). During this decade, a growing evidence base has emerged suggesting that group programs in NSW are making a difference to rates of re-offending. This work is methodologically taxing, but a number of recently completed studies have used the techniques such as propensity score matching to create control groups and survival analysis to measure time to re-offending (Belling, 2013; Fraser, 2013).

The major challenges still facing the OPU are cultural and systemic.

The first is convincing the agency to acknowledge legitimate professional expertise in the delivery of group programs. Traditionally, these have been facilitated by a variety of staff as one of many roles and many staff believe that this is an adequate way to proceed. This results in some staff being inimical to the requisite training and to ongoing program supervision. Despite this, at the time of writing there is still the issue of multiple staff categories (13 in all) delivering programs. This presents significant challenges to training, supervision and quality monitoring. Although the situation has improved, large numbers of staff are trained whose primary role is something other than the facilitation of group programs. Given the current industrial restructuring of the agency, it is not uncommon for these staff, especially Probation and Parole officers (now called Community Corrections Officers), to have moved offices or roles with months or even weeks of completing training and therefore to be unavailable to facilitate.

The second is a related systemic issue concerning the locus within CSNSW where policy and practice about group work are determined. The Division of Offender Management and Policy, which includes the OPU, is separate from the two operational Divisions of Custodial and Community corrections. Offender Management has no direct line management authority over staff who deliver programs, with the exception of some 30 of the

105 J. of Practice Teaching \& Learning 12(3), pp.93-109. DOI: 10.1921/7902120302. @ w\&bb 2014 
specialist Program Facilitators who are around 40 in total. All of the staff who work in the operational Divisions, including those who deliver group programs, have line managers whose priorities may not be aligned with the aspirations of the Offender Management and Policy Division. Their key performance indicators, for example, may be quantitative rather than qualitative and this may work against the pursuit of excellence in group program delivery. Their workload priorities may be so pressing that other activities take precedence over group programs.

The third challenge is to achieve further recognition across the agency of the OPU as the legitimate arbiter of which group programs may be run. While major change has been achieved, there is still not 100\% compliance with this principle. This may be partly an issue of resources. In Australia the concept of the 'tyranny of distance' is often appealed to as a factor in social phenomena, including service provision. It refers to the fact that the Australian population is widely dispersed over large distances. In NSW for example, the capital city Sydney on the East Coast is around $1200 \mathrm{kms}$ from Broken Hill on the Western border while Wentworth in the South West is some $1800 \mathrm{kms}$ from Brunswick Heads on the North Coast. This dispersal poses significant challenges especially when it comes to program quality, support and supervision. With around 100 locations across the state where group programs are delivered, it is likely that the OPU will struggle to provide comprehensive support and supervision without an expansion in numbers. Whereas training can be delivered in groups and off-site, group work supervision requires at least some measure of individual workplace contact and individual feedback.

This paper is subtitled 'Some reflections on being neat in messy places' as a homage to the work of David Rosenhan (1973) and to highlight the tension between good practice aspirations and real world challenges. The OPU based its approach on the available literature and tried to carry with it as many as possible of 6,000 colleagues. The strategy is good; the implementation is fraught with the slings and arrows of competing priorities. The only real measure of success will be the impact that OPU has had, and continues to have on re-offending. The measurement of this, as discussed, is methodologically challenging, but there is room for cautious confidence that improvements in data collection and analysis will enable the Agency to ascertain whether and how much group work programs matter. Do they reduce the rate of re-offending? Do they reduce the severity of the eventual re-offence? Do they delay the commission of another offence? Do they contribute to community safety? Do they deliver value for money?

106 J. of Practice Teaching \& Learning 12(3), pp.93-109. DOI: 10.1921/7902120302. @ w\&b 2014 
We cannot yet give definitive answers to these questions in NSW. What is heartening is that we are beginning to examine data with a view to answering them in a way that was simply not possible ten years ago. We may not yet know how we measure up, but we do know what we are measuring.

\section{References}

Andrews, D. A. \& Bonta, J. L. (2005). LSI-R Level of Service Inventory - Revised: Assessment of risk/needs for offender treatment, planning, and placement-User's guide. Toronto: Multi-Health Systems

Andrews, D. A. \& Bonta, J. (2006). The Psychology of Criminal Conduct (4th ed.). Cincinnati, OH: Anderson

Aos, S., Miller, M. \& Drake, E. (2006). Evidence-Based Public Policy Options to Reduce Future Prison Construction, and Crime Rates. Olympia: Washington State Institute for Public Policy

Belling, R. (2013). Functional Literacy, Functional Lives: Are prison-based adult reading interventions associated with a reduction in recidivism? (Unpublished Master's thesis), University of New South Wales, Sydney, Australia

Caruana, R. (1998). Best Practice Framework for Program Intervention. Probation and Parole Service Memo 31/98

Corrective Services New South Wales (CSNSW). (2012). Compendium of Correctional Programs in New South Wales. Available from http://www.correctiveservices.nsw. gov.au/

Department of Corrective Services. (2003, April). Strategic Framework for Program Accreditation (Unpublished document)

Delaney, J. (2011). An evaluation of the NSW Domestic Abuse Program. (Unpublished Master's thesis), University of New South Wales, Sydney, Australia

Di Pietro, G. (2005). The Drug and Alcohol Addictions Program. Corrective Services New South Wales, Sydney

Fraser, M. (2013). An evaluation of the Controlling Anger and Learning to Manage it (CALM) program: its impact on re-offending within a NSW custodial population (Unpublished Master's thesis), University of New South Wales, Sydney, Australia

Goggin, C. \& Gendreau, P. (2006). The implementation and maintenance of quality services in offender rehabilitation programmes. In C. R. Hollin \& E. J. Palmer (Eds.), (pp. 209-246). Offending Behaviour Programmes: Development, application and controversies. UK: John Wiley

Holland, L. \& Sallabank, J. (2011, Aug). The emerging role of the specialist

107 J. of Practice Teaching \& Learning 12(3), pp.93-109. DOI: 10.1921/7902120302. @ wEb 2014 
Program Facilitator within the context of Corrective Services NSW. OPU Practice Development Series No. 20. Corrective Services NSW

Howells, K., Heseltine, K., Sarre, R., Davey, L. \& Day, A. (2004). Correctional Offender Rehabilitation Programs: The national picture in Australia. Criminology Research Council grant (4/02-03). Available from http://www. criminologyresearchcouncil.gov.au/reports/200203-04.html

Latessa, E. J. (2009). What Works And What Doesn't In Reducing Recidivism For Juvenile Offenders: Applying the principles of effective intervention. [Powerpoint slides]. Available from http://www.google. com.au/search?q=program+fidelity+recidivism \&hl=en\&rls=com. microsoft: $*$ prmd=ivns\&ei=bZLzT-fOAYjZigeviOHqBg\&start=20\&sa=N . Lipsey, M. W. \& Cullen, C. T. (2007). The effectiveness of correctional rehabilitation: A systematic review. Annual Review of Law and Social Sciences, 3, 297-320

Lowenkamp, C. T., Latessa, E. J. \& Holsinger, A. M. (2006). The risk principle in action: What have we learned from 13,676 offenders and 97 correctional programs? Crime \& Delinquency, 52, 1, 77-93

Offender Programs Unit (2010). Program Supervision Framework. Available from http://www.correctiveservices.nsw.gov.au/offendermanagement/offender-services- and-programs

Offender Programs Unit. (2012). Program Accreditation Framework. Available from http://www.correctiveservices.nsw.gov.au/_data/assets/pdf_ file/0005/439907/Accr editation-Framework-Version-5-2-18-September.pdf

Offender Services and Programs, Corrective Services NSW (February 2012). Compendium of Assessments ( $1^{\text {st }}$ ed.). Sydney: CSNSW. Available from http:// www.correctiveservices.nsw.gov.au/_data/assets/pdf_file/0009/436761/Com pendium-of-Assessments-1st-Edition-Final.pdf

Offender Programs Unit. (2005). Compendium of Correctional Programs in NSW. Sydney: Department of Corrective Services. Available from http://www. correctiveservices.nsw.gov.au/_data/assets/pdf_file/0012/439896/2012 -Compendium-of-Programs-revised-17-Sept-2012.pdf

O'Sullivan, K. (1996). A Systemic Approach to Violence in a Correctional System. Paper presented at the 29th Annual Conference of the New Zealand Psychological Society, 1996, Christchurch, New Zealand

O'Sullivan, K. (2006). Introducing Evidence-Based Correctional Programs in NSW: What worked. OPU Practice Development Series No.1. Corrective Services NSW O'Sullivan, K., Haggett, R. \& Clark, J. (1997). Personal Effectiveness Program, Vols 1 E 2. Sydney: Atelier

Rosenhan, D. L. (1973). On being sane in insane places. Science, 179, 250-8

108 J. of Practice Teaching \& Learning 12(3), pp.93-109. DOI: 10.1921/7902120302. @ wEb 2014 
Shaffer, D. K. \& Pratt, T. C. (2009). Meta-analysis, moderators, and treatment effectiveness: The importance of digging deeper for evidence of program integrity. Journal of Offender Rehabilitation, 48, 2, 101-119

Skeem, J. L., Polaschek, D. L. L., \& Manchak, S. (2009). Appropriate treatment works, but how?: Rehabilitating general, psychopathic, and high-risk offenders. In J. L. Skeem, K. S. Douglas, \& S. O. Lilienfeld (Eds.), Psychological Science in the Courtroom: Consensus and controversy (pp. 358-384). New York, NY: Guilford Press

Sullivan, H. S. (1953). The Interpersonal Theory of Psychiatry. New York: W. W. Norton \& Company

Ward, T., \& Stewart, C. A. (2003). The treatment of sex offenders: Risk management and good lives. Professional Psychology, Research and Practice, 34, 353-360

Weiss. J.C. (1988). The D-R Model of Coleadership of Group. Small Group Behavior. Vol 19 (1),117-125

Winogron, W., Van Dieten, M. \& Gauzas, L. (1997). Controlling Anger and Learning to Manage It. Toronto: Multi Health Systems

Yalom, I.D., Leszcz, M. (2005). The Theory and Practice of Group Psychotherapy. (5 $5^{\text {th }}$ ed.). New York: Basic Books. 